\title{
EDUCAÇÄO BIMODAL NO CURSO DE PEDAGOGIA: APRENDIZAGENS EM ESTATÍSTICA APLICADA À EDUCAÇÃO
}

\section{Suely Scherer}

CDD: 371.39445

\section{RESUMO}

O presente artigo apresenta e analisa uma estética de Educação Bimodal - parte presencial e parte virtual -, identificando atitudes, espaços e ações de professores e alunos que favorecem aprendizagens e comunicações em ambientes presencias e virtuais, coerente com a estética da complexidade. $\mathrm{O}$ estudo foi desenvolvido a partir da epistemologia genética, a teoria autopoiética, a interdisciplinaridade e a educação libertadora. Para fins de apresentação e análise dessa estética, são discutidos os movimentos de aprendizagem e comunicação de alunos e professora - a pesquisadora -, na disciplina de Estatística Aplicada à Educação, no curso de Pedagogia de um Centro Universitário de Santa Catarina.

\section{PALAVRAS-CHAVE}

Educação bimodal; Aprendizagem; Comunicação; Ambientes virtuais

\section{BIMODAL EDUCATION IN THE PEDAGOGY COURSE: LEARNIGS IN STATISTICS APPLIED TO EDUCATION}

\begin{abstract}
This article presents and analyzes the aesthetics of blended learning - half held in classroom, half held virtually - identifying attitudes and places as well as students and teachers actions in order to create a favorable atmosphere for the learning and communication processes which take place in virtual and face to face environments, being coherent with the aesthetics of complexity. This study was developed based on theories such as an genetic epistemology, autopoietic theory, interdisciplinarity and libertarian education. In order to present and analyze the aesthetics, learning and communication movements occurred among students and teacher - who was the researcher - involved in a "Estatística Aplicada à Educação", offered by the Education Course at Centro Universitário of Santa Catarina.
\end{abstract}

\section{KEYWORDS}

Blended learning; Learning process; Communication; Virtual environment 


\section{INTRODUÇÃO}

O presente artigo, recorte de minha tese de doutorado (SCHERER, 2005), propõe, a partir de estudos sobre a epistemologia genética, a complexidade, a interdisciplinaridade e a educação libertadora, uma estética possível para uma Educação Bimodal - parte presencial e parte virtual -, favorecendo a aprendizagem e a comunicação entre professores(as) e alunos(as) em ambientes educacionais híbridos. Para fins de apresentação e análise dessa estética, são discutidos os movimentos de aprendizagem e comunicação de alunos e professora - a pesquisadora -, na disciplina de Estatística Aplicada à Educação, no curso de Pedagogia, em um Centro Universitário de Santa Catarina.

Ao me deparar com a portaria no 2.253 de 18 de outubro de 2001 do MEC, que possibilita que $20 \%$ da carga horária total das aulas ministradas em um curso reconhecido sejam ministradas na modalidade de Educação a Distância, me questiono: quais as possibilidades das Instituições de Ensino Superior (IES) favorecerem-se com esta portaria sem reproduzirem o mesmo modelo de educação desenvolvido nos ambientes presenciais? Como podemos explorar as possibilidades da Educação Bimodal, avançando a partir dos modelos de educação existentes? Quais atitudes do educador ou educadora podem ser identificados como relevantes para comunicação e aprendizagens em uma proposta de Educação Bimodal presencial/ a distância? Que atitudes dos alunos e alunas contribuem para aprendizagens e comunicações no processo de Educação Bimodal? Qual a contribuição da estética do material impresso e do ambiente virtual para a aprendizagem dos alunos em relação aos conteúdos discutidos?

É a partir destas e outras inquietações que apresento e discuto a educação bimodal neste artigo, com o objetivo de apresentar e analisar uma estética para a Educação Bimodal, identificando atitudes, espaços e ações de educadores e educandos, em um curso de formação de professores, que favoreçam aprendizagens e comunicações em ambientes presencias e virtuais, coerente com a estética da complexidade.

O termo estética é usado no presente artigo, segundo Maffesoli (1999), como o termo mais coerente para descrever o ambiente, em que tudo tem importância: os detalhes, os fragmentos, as pequenas coisas, os diversos acontecimentos. Assim, considera-se aqui que o termo estética representa forma e vida, representa o fluxo, o movimento, algumas vezes 
caótico, contraditório; representa a forma e o movimento do ser humano, dos ambientes e das relações que se estabelecem.

\section{A PROPOSTA DE EDUCAÇÃO BIMODAL EM ESTATÍSTICA APLICADA À EDUCAÇÃO}

Como educadora, ministro a disciplina de estatística aplicada à educação, no curso de pedagogia, foco da pesquisa que discuto neste artigo, usando ambientes virtuais, desde 2002. Neste artigo, me deterei aos movimentos de aprendizagem de 38 alunas do terceiro semestre do curso, formandas do ano de 2006.

A disciplina de Estatística Aplicada à Educação é, desde 2001, estudada pelos alunos no terceiro semestre do curso de Pedagogia. Esses alunos participam no primeiro semestre do curso da disciplina "Aprendizagem Cooperativa em Ambientes Informatizados", na qual são convidados a participar de discussões em relação ao uso de computadores na educação. Assim, no terceiro semestre do curso, poucos alunos possuem dificuldades em relação ao uso do computador. No entanto, como a disciplina de Estatística Aplicada à Educação é a primeira disciplina do curso que discute conceitos matemáticos, a barreira em relação à aprendizagem desses conceitos é bastante grande em alguns casos, motivada sempre, pela história escolar/de vida dos alunos. Essa barreira precisa ser quebrada ou "amolecida", pois falamos de alunos, futuros professores e professoras, que irão ensinar matemática a crianças.

A disciplina tem por objetivo a aprendizagem de conceitos da estatística, ao proporcionar vivências e reflexões para o uso desses nos diferentes campos do conhecimento como forma de organizar, registrar, analisar e comunicar diferentes informações necessárias para a compreensão do mundo e o exercício da cidadania. O que se objetiva é que, ao refletirem sobre suas aprendizagens, os alunos criem novas perspectivas para a educação matemática de crianças da educação infantil e das séries iniciais do ensino fundamental.

Para atingir o objetivo proposto na disciplina, desde 2000, o fio condutor da disciplina é um projeto de aprendizagem coletivo, cujo problema de pesquisa é definido em parceria com o grupo de alunos, no primeiro dia de aula. Em torno desse projeto, os conhecimentos da disciplina são discutidos e, pela vivência de um processo de aprendizagem 
diferenciado, objetiva-se que os alunos planejem e desenvolvam ações para o ensino da estatística na educação infantil e séries iniciais do ensino fundamental.

O processo de ensino e aprendizagem da disciplina se desenvolve por propostas de trabalhos coletivos e individuais, debates, pesquisa de campo, análise de dados, exposições minhas, numa comunicação continuada, objetivando a compreensão dos conceitos e a linguagem da Estatística e da Matemática como um todo. São usados vários recursos, dentre eles, materiais manipuláveis e o computador, para a aprendizagem dos conceitos que vão emergindo das discussões do projeto de pesquisa ou outros. Assim, os alunos aprendem conceitos estatísticos de forma contextualizada, pois necessitam construir esses conceitos para conseguir resolver o problema que elaboraram. Por este motivo, ao elaborarem a problemática a ser discutida durante o semestre, sugiro que eles pensem em uma temática que necessite do levantamento de dados junto a uma população específica, ou seja, que desencadeie uma pesquisa pelo método estatístico.

Ao propor este processo, tenho por objetivo possibilitar a estes alunos vivenciarem um processo diferente dos vividos por eles nas escolas de Educação Básica, os quais, em sua maioria, representam a educação bancária anunciada por Paulo Freire. O que se espera é que estes professores em formação, ao vivenciarem esse processo de aprendizagem, possam compreender, sentir e ensinar matemática de forma mais contextualizada, interdisciplinar e significativa. Como afirma Silva (2000), os futuros professores tendem a "copiar" as aulas de seus professores formadores.

Neste contexto, a disciplina é organizada e implementada em um processo de Educação Bimodal, em diferentes espaços: presenciais, ambiente virtual de aprendizagem e material impresso (SCHERER, 2004). Os movimentos de comunicação e aprendizagem do grupo de alunas que analiso neste artigo desenvolveu 35,29\% da carga horária da disciplina na modalidade de Educação a Distância. Isto foi possível, porque os $20 \%$ sobre a carga horária total do curso, permitidos para esta modalidade pelo MEC (Portaria $\mathrm{n}^{\mathrm{o}} 4.059$ de 10 de dezembro de 2004), não foram usados em sua totalidade pelas demais disciplinas. Assim, ao todo foram 17 (dezessete) encontros, sendo 11 (onze) momentos presenciais e 6 (seis) momentos a distância, alternados ao longo da disciplina, exceto o final da disciplina em que foram organizados mais encontros presenciais. A seguir discuto mais sobre a organização dos ambientes e materiais da disciplina. 


\section{O AMBIENTE VIRTUAL, O MATERIAL IMPRESSO E A ARTICULAÇÃO ENTRE ESPAÇOS}

Inicialmente vou discutir a organização do ambiente virtual da disciplina de Estatística Aplicada à Educação. Ao propormos um processo de Educação Bimodal, temos de fazer a escolha das tecnologias a serem utilizadas no ambiente virtual. O ambiente virtual pode ser criado a partir de plataformas de código aberto como a plataforma do Teleduc, Learnloop, Moodle, entre outras, ou plataformas pagas como a Webct, Aulanet, ... ou ainda a partir de plataformas criadas na própria instituição. Além dessas possibilidades, podemos criar um ambiente virtual de aprendizagem a partir de ambientes da WEB 2.0, como blogs, wikis, orkut, dentre outros. Por outro e do mesmo lado, pode-se usar recursos como e-mail, listas de discussão, MSN, Netmeeting, ...

No entanto, a escolha precisa ser feita a partir do objetivo que temos na disciplina e/ou curso. Neste sentido, considerei importante para o grupo de alunas do curso de pedagogia, organizar um ambiente virtual, em plataforma própria. Mas, o processo todo poderia ter sido organizado na plataforma moodle. No ambiente virtual foram disponibilizados espaços como: Agenda, Webfólios, Fóruns, Projeto Coletivo, e Webteca.

O espaço da agenda é o espaço que apresenta as ações a serem desenvolvidas em determinado período, pelo grupo de pessoas que está fazendo parte da disciplina: professora e alunas. Assim, a cada período, as ações são alteradas, sempre articulando os momentos presenciais e os momentos a distância: espaços virtuais, pesquisa de campo, leitura de material impresso. O espaço dos webfólios é individual, no qual o aluno registra o seu processo de aprendizagem, bem como disponibiliza suas produções, e comunica-se com o professor. O webfólio configura-se em um espaço individualizado de aprendizagem e de reflexão, diferente o espaço do fórum, que é espaço de debate e aprendizagens em cooperação e colaboração com o grande grupo.

O espaço do Projeto Coletivo foi um espaço destinado às informações e discussões em torno da pesquisa coletiva desenvolvida na disciplina. Neste espaço, as informações foram atualizadas continuamente e as discussões aconteceram em grupos menores e em grande grupo. É importante destacar o tópico em que se fez a discussão da justificativa da escolha do projeto. Nele, as alunas construíram a 38 mãos e mais a da professora, uma justificativa para o 
projeto que iriam desenvolver. O mesmo aconteceu com o texto das considerações finais da pesquisa.

O espaço da webteca deu acesso a materiais usados na disciplina. Alguns materiais do livro, material impresso da disciplina, ganham novos movimentos a partir da linguagem da informática, indicando novas possibilidades hipertextuais, de leitura e de aprendizagem.

A organização de cada espaço de aprendizagem, o seu design, é que convida ao diálogo, ao aconchego, os que ao passarem pelo "lugar", tornam-se os seus "habitantes", (re) construindo-o. Portanto, em uma proposta de Educação Bimodal, temos de criar o espaço virtual, com flexibilidade de formas, cores e movimentos, criando o espaço de cada grupo numa perspectiva de significados para cada um dos sujeitos envolvidos. O design dos espaços é importante por mexer com nossas emoções, que são "disposições corporais dinâmicas que definem os diferentes domínios de ação em que nos movemos" (MATURANA, 2001, p.15), elas representam o motor da aprendizagem.

Além do ambiente virtual, para os processos a distância, as alunas tiveram a sua disposição um livro (SCHERER, 2004), material impresso desenvolvido especificamente para a proposta de Educação Bimodal da disciplina. A necessidade do material impresso surgiu devido a alguns alunos do curso de pedagogia não terem acesso à internet em todos os seus horários disponíveis para estudo, e, ter o material impresso em mãos, pode contribuir para flexibilizar horários e espaços de estudo.

Ao escrever, ao criar o material impresso, procurei centrar a linguagem no diálogo, na comunicação com os alunos e não apenas na ação de informar. O professor, que é autor de materiais impressos para $\mathrm{EaD}$, precisa aprender a comunicar-se com o estudante. Nas palavras de Freire (1992, p.67) falamos da dialogicidade:

[...] a expressão verbal de um dos sujeitos tem de ser percebida dentro de um quadro significativo comum ao outro sujeito. Se não há este acordo em torno dos signos, como expressões do objeto significado, não pode haver compreensão entre os sujeitos, o que impossibilita a comunicação.

Aqui Freire fala de expressão verbal, mas temos de compreendê-la na educação a distância, como também expressão escrita. E é pela dialogicidade que temos de escrever o material em um movimento de pergunta e não apenas de respostas. Autores como Soletic (2001) também considera importante criar rupturas na leitura linear de um texto, com a 
formulação de perguntas. Esta dialogicidade também inclui criar o material a partir da história dos estudantes que irão utilizá-lo. Nesse sentido, ao escrever o material impresso da disciplina, considerei que as alunas da disciplina de estatística aplicada à educação não tinham tido contato ainda com a aprendizagem de conceitos matemáticos numa perspectiva de construção de conceitos, pois viveram em uma escola que apenas os reproduzia. Além disso, considerei que elas participavam de um curso de formação inicial de professores, que as colocava em contato com a Matemática pela primeira vez, na disciplina de Estatística Aplicada à Educação.

E foi neste movimento de organização de ambiente virtual, de material impresso, de momentos presenciais, que a disciplina de Estatística Aplicada à Educação foi proposta, constituindo-se uma Educação Bimodal, em um processo híbrido:

\begin{abstract}
Híbrido - do grego hybris, cuja etimologia remete a ultraje, correspondendo a uma miscigenação ou mistura que viola as leis naturais, ultrapassa as fronteiras. A palavra remete ao que é originário de espécies diversas, miscigenado de maneira anômala e irregular. Híbrido é também o que participa de dois ou mais conjuntos, gêneros ou estilos. Considera-se híbrida a composição de dois elementos diversos, anomalamente reunidos para originar um terceiro elemento que pode ter as características dos dois primeiros reforçados ou reduzidos. (RAMAL, 2002, p.254).
\end{abstract}

Esta Educação Bimodal, como movimento híbrido, não necessariamente representa apenas harmonia, funcionalidade, mas também dissonância, oposição e antagonismo. É inegável que em toda organização complexa há coerções sobre as partes, que impõem restrições e servidões, e essas fazem com que ela perca ou acabe por inibir algumas qualidades ou propriedades, afinal, esse movimento também faz parte da complexidade de sua constituição.

Assim, cada um dos espaços educacionais, sejam eles presenciais ou a distância, possuem características particulares que podem favorecer ou dificultar o processo de hibridação. O que tenho proposto é que, pela diversidade dos ambientes, podemos hibridizálos, torná-los um movimento único de ensino e de aprendizagem em cursos, disciplinas ou programas, considerando o princípio hologramático do pensamento complexo. Segundo Morin at al. (2003), o princípio hologramático implica em percebemos que cada parte contém praticamente a totalidade, sendo que a parte está no todo ao mesmo tempo em que o todo está na parte. Neste sentido, nos momentos presenciais percebemos também os virtuais, e nos 
virtuais vemos também os presenciais, sem deixar de sentir e perceber cada um dos espaços em particular.

Nesse movimento híbrido, ao vivenciar cada uma das partes na Educação Bimodal, algumas alunas da disciplina de Estatística Aplicada à Educação se sentiram melhor nos ambientes presenciais e outras preferiram os ambientes virtuais. É por este motivo que a hibridação é uma alternativa para a educação. A particularidade do ambiente presencial, conhecido por todos, e pertencente à cultura das pessoas desde que nasceram, é um movimento bastante intenso e que não podemos abandonar, apenas redimensionar. Assim, os momentos presenciais da disciplina foram usados para fazer as articulações, para olhar para o todo, observar, analisar olhares, expressões, sentir a energia oriunda de cada um e do grupo. Foram momentos de confirmação, de resgate e de aprofundamento do lido, escrito, discutido e produzido no ambiente virtual. Essa confirmação ocorreu no ver, no tocar, no sentir, no movimento corporal...

O ambiente virtual, por outro lado e do mesmo lado, possibilitou o olhar atento e demorado para cada um dos sujeitos, para os movimentos de aprendizagem presentes em seus registros em alguns momentos, que não se perdem quando o som ou a memória se perde no tempo. Este ambiente possibilitou o olhar detalhado sobre as individualidades dos sujeitos, a sua forma de viver junto com os outros, colaborando, cooperando, ou registrando os seus processos de aprendizagem. No ambiente virtual, todos as alunas tinham o direito a voz, o tempo todo, podendo falar/escrever e serem ouvidas/lidas sem esperas, sendo necessário apenas o acesso ao ambiente. Foram momentos de confirmação, de resgate e aprofundamento dos movimentos percebidos no ambiente presencial; foram momentos em que pude desafiar cada aluna em suas certezas, fazendo a pergunta que promovia a reflexão, a aprendizagem.

Estas perguntas também foram feitas no presencial, mas no virtual eu tinha um tempo diferente, de pesquisa, de análise, pois eu passava de um espaço ao outro procurando evidências, lembrando dos momentos presenciais. Assim, o desafio foi mais pensado e remetia a desafios mais pensados no presencial. Esse movimento híbrido fez com que os tempos também se hidridizassem, além dos espaços, pois tudo consistia em um movimento contínuo, sem quebras ou paradas, foi um tempo de aprender. E o tempo não era apenas cronos, tempo de controle, mas também kairós, "tempo que subverte a ordem de cronos, que se aproveita da imprevisibilidade, tempo flutuante. Em cronos submetemo-nos a cronogramas. Em kairós, à oportunidade de criar" (FAZENDA, 2001, p.29). 
Portanto, a estética da Educação Bimodal está na articulação de dois espaços - o presencial e o virtual -, na complementaridade dos movimentos possíveis em cada um deles, não excluindo, aproveitando todos os movimentos, tecnologias e linguagens. Os habitantes que tanto queremos para os espaços da educação são aqueles que usam diferentes linguagens (incluindo a linguagem do silêncio) que, como professores, temos de aprender a compreender, para então desafiar e contribuir com a aprendizagem de todos e de cada um em especial.

\section{ATITUDE E AÇÃO DE PROFESSOR E ALUNOS: HABITANTES, VISITANTES OU TRANSEUNTES?}

Após apresentar brevemente a organização e articulação de espaços e materiais da disciplina de Estatística Aplicada à Educação, irei apresentar e analisar alguns movimentos de aprendizagem e comunicação observados na disciplina. Para realizar a análise, caracterizo a participação de alunos e professores, em ambientes de aprendizagem presenciais ou virtuais em: habitantes, visitantes e transeuntes. Os habitantes são aqueles que se responsabilizam pelas suas ações e pelas dos parceiros, buscando o entendimento mútuo, a ação comunicativa, o questionamento reconstrutivo; o habitante está sempre sendo parte (sentido dinâmico) do ambiente. Portanto, o encontramos sempre no ambiente, pois ele também vive lá, observando, falando, silenciando, postando mensagens, refletindo, questionando, produzindo, sugerindo, contribuindo com a história do ambiente, do grupo e dele.

Os visitantes são aqueles alunos(as) e professores(as) que participam do ambiente de aprendizagem com a intenção de visitar. Quando visitamos um ambiente, o fazemos impelidos por algum dever, por afeto ou por amizade. A ação livre para participar nem sempre está presente, lembrando que a palavra visitar vem do latim visitare, iterativo de videre, ver. As visitantes participaram apenas para observar o que estava acontecendo, sem se coresponsabilizar com o ambiente, com o outro, ou com a produção coletiva. Alguns deles chegam a colaborar, mas sem chegar a cooperar.

Além de habitantes e visitantes, temos os transeuntes. Os transeuntes dos ambientes de aprendizagem são aqueles alunos(as) e professores(as) que passam pelo ambiente. Alguns entram, circulando pelos espaços, outros apenas passam. Eles são passantes, nem visitantes, e nem habitantes. A origem da palavra transeunte vem do latim transire, passar além, passar de um lugar para outro, sem parar, é alguém de passagem. Os transeuntes passam pelo ambiente em um ou mais momentos, às vezes param para observar, mas sem se 
deter em nenhum espaço em especial, sem se responsabilizar, sem apreender para si o ambiente, sem colaborar ou cooperar. Se notada a presença deles, eles se relacionam alheios ao grupo e ao ambiente, pois são apenas passantes, nem visitantes e nem habitantes do lugar.

O professor que é habitante dos ambientes contempla, propõe, articula, comunica e questiona. Ao contemplar, "ad-miramos", segundo Freire (1992), vemos de "dentro" e, desse "interior", separamos o que observamos em suas partes e voltamos a "ad-mirar" o todo, apropriando-nos do contexto, inserindo-nos nele. O movimento de "ad-mirar" é um ato de conhecer, de compreender, de leitura da palavra, do texto, do contexto, e do mundo. É um movimento que objetiva a mudança pelo ato de conhecer, compreender e questionar.

Se o professor é apenas visitante da aula que coordena, nem sempre chega no momento adequado, com a questão que desequilibra o aluno em suas certezas. E sendo transeunte, dificilmente questiona ou se posiciona, prefere a não-diretividade descompromissada, pautada na epistemologia apriorista, detalhada por Becker (2001). Portanto, precisamos ser e formar educadores habitantes, com atitude interdisciplinar.

É uma atitude ante alternativas para conhecer mais e melhor; atitude de espera ante os atos não consumados, atitude de reciprocidade que impele à troca, que impele ao diálogo, ao diálogo com os pares idênticos, com pares anônimos ou consigo mesmo, atitude de humildade ante a limitação do próprio saber, atitude de perplexidade ante a possibilidade de desvendar novos saberes; atitude de desafio, desafio em redimensionar o velho; atitude de envolvimento e comprometimento com os projetos e com as pessoas neles envolvidas; atitude, pois de compromisso em construir sempre da melhor forma possível; atitude de responsabilidade, mas sobretudo, de alegria, de revelação, de encontro, enfim, de vida. (FAZENDA, 2003, p.75).

Em minha tentativa de ser habitante dos ambientes educacionais, com atitude interdisciplinar, que analiso os registros deixados por um grupo de 38 alunas habitantes, visitantes ou transeuntes, na disciplina de Estatística Aplicada à Educação. Me deterei, neste artigo, a analisar alguns registros, resgatados diretamente do webfólio de uma das alunas habitantes (H.H.B.), e, do espaço do fórum, no ambiente virtual de aprendizagem da disciplina.

Os webfólios individuais, espaços virtuais destinados aos registros das aprendizagens dos alunos, de suas reflexões, de suas emoções, sentimentos e desejos, foram espaços que possibilitaram que eu apreendesse as alunas que o habitavam. No entanto, a aluna precisava estar habitando o espaço, pois apreendemos muito pouco de um aluno que apenas 
visita ou está de passagem pelo ambiente. O habitar de professor e aluno neste espaço, possibilita o "estar junto" virtual.

O "estar junto" virtual envolve o acompanhamento e assessoramento constante do aprendiz no sentido de poder entender o que ele faz, para ser capaz de propor desafios e auxiliá-lo a atribuir significado ao que está realizando. Só assim ele consegue processar as informações, aplicando-as, transformando-as, buscando outras informações e, assim, construindo novos conhecimentos. (VALENTE, 2000, p.109).

No movimento de "estar junto" virtual iniciei os encontros a distância da disciplina. A primeira proposta, no ambiente virtual, foi desafiar as alunas a justificar os cálculos que apresentavam ao resolver uma situação problema proposta por mim ou por elas, ao discutir o conceito de porcentagem. Para evidenciar o movimento de aprendizagem e a importância do professor ser habitante dos espaços, faço a seguir um recorte de um movimento dialógico, entre a aluna habitante H.H.B. e eu, no espaço de seu webfólio individual. Inicio trazendo as certezas provisórias que a aluna apresenta no primeiro momento da interação.

“09/03- [...] Eu faço o cálculo de percentual assim: Na nossa sala de aula tem 40 meninas, 20\% são casadas, quantas são essas 20\%? Bem, 40 meninas corresponde a 100\%, então $20 \%$ corresponde a $x$. Multiplico o 100 pelo $x$ e 40 pelo 20. Vai ficar $100 x=800$, resultado final, 8 meninas casadas. H.H.B.”

O cálculo de porcentagem feito por ela evidencia que está apenas executando um procedimento, sem pensar em sentidos e significados. Este é o momento do professor habitante questionar as certezas da aluna, de forma a desencadear um processo de dúvida em relação as suas certezas. Afinal, a repetição de tarefas, na área de matemática, é muito conhecida, e os alunos na maioria das vezes são levados a repetir vários exercícios, sem saber o que estão fazendo, sem serem questionados sobre como estão pensando. Assim, a minha atitude de questionar as alunas sobre "os passos" de sua ação ao resolver o problema, conforme Becker (2003), favorece a abstração reflexionante - "ato mental de reconstrução e reorganização sobre o patamar superior daquilo que foi transferido do patamar inferior" (PIAGET apud BECKER, 2003, p.77). 
Assim, procurei apreender a aluna, ao lançar-lhe uma pergunta.

"10/03- Quero saber um pouco mais sobre a tua "conta"...Você sabe por que se "Multiplica o 100 pelo x e 40 pelo 20"? Qual o motivo? Fico esperando...Beijos, Suely"

Inicialmente, a aluna ofereceu resistência ao ser questionada.

“13/03- Bem, eu multiplico assim, pois foi assim que aprendi. Esta semana a T.H., ensinou-me uma maneira de calcular a porcentagem, mas não sei se consegui aprender certo. Vou tentar explicar... Uma calça custa $R \$ 30,00$ e possui $20 \%$ de desconto, quanto custa a calça? Eu multiplico o 3x2=6, e não eu faço 30-6=24, a calça vai custar $R \$ 24,00$. Está certo?!?!!?!?... Abraços... H.H.B.”

Como professora, eu estava apreendendo a aluna, e fiz um novo questionamento buscando mais uma vez o desequilíbrio cognitivo da aluna em relação às suas certezas...

Suely”

“13/03- OK. Mas, tenho mais perguntas... Por que multiplicar o 3x2=6? Abraços,

Neste momento, surgiu o movimento inicial de desequilíbrio cognitivo da aluna, mas ainda resistente, percebido em sua escrita e nas representações simbólicas.

"20/03- Bem, vou tentar explicar outra vez sobre porcentagem. Conforme está escrito no seu texto, "1\% é pegar um de cada 100 dos elementos que queremos obter o percentual. Ou,para obetr $1 \%$ de uma quantidade podemos dividí-la por 100". Eu multipliquei o 3 por 2, pois dividi 30 por 100 que deu igual a 0,3, depois peguei esse valor correspondente a $1 \%$ e multipliquei pelo $20 \%$ que é o percentual que quero. Agora ficou entendido?????!!!! [...]. Abraços, H.H.B.!!!"

A minha responsabilidade frente ao processo de aprendizagem da aluna, caracterizando a atitude de professora habitante, me mobilizou a continuar o diálogo.

“23/03- [...] Quanto a tua justificativa do 3x 2, não compreendi em que momento da explicação que segue, fazes o 3x2. Lembre-se que esta explicação é importante, pois considere que sou uma aluna sua e preciso compreender a tua explicação. "pois dividi 30 por 100 que deu igual a 0,3, depois peguei esse valor correspondente a 1\% e multipliquei pelo $20 \%$ que é o percentual que quero." Gostaria que você detalhasse aqui mais exemplos sobre os teus estudos em porcentagem. Suely"

“27/03- [...] Eu multiplico 3 por 2, pois foi assim que aprendi, também não sei porque, nunca me explicaram o porquê, mas o importante é que chega no mesmo resultado do que se eu fosse fazer na calculadora. É claro que isso é um pouco complicado para explicar para as crianças. Como eu disse na primeira vez que eu entrei no webfólio, nã̃ consigo aprender muito bem só lendo textos, por isso se você comentasse em sala de aula 
como poderia fazer para explicar para as crianças, eu entenderia um pouco mais e teria mas argumentos para comentar. Abraços, H.H.B.!!!!"”

Aqui percebe-se a importância da articulação entre os dois espaços (presencial e virtual), do uso de diferentes materiais, da dialogicidade de que fala Freire (2001, p.80).

\begin{abstract}
"A dialogicidade é cheia de curiosidade, de inquietação. De respeito mútuo entre os sujeitos que dialogam. A dialogicidade supõe maturidade, aventura do espírito, segurança ao perguntar, seriedade na resposta. No clima de dialogicidade, o sujeito que pergunta sabe a razão por que o faz."
\end{abstract}

E neste movimento, continuamos a dialogar, a aprender, aqui e nos demais espaços da disciplina que habitávamos. E, depois de algumas semanas...

"11/04- Bom dia e Feliz Páscoa!!! Tens razão professora, é 20 x 0,3 ao invés de 0,3 x 20, eu sempre me confundo com isso. Penso que vai ser um pouco complicado eu explicar esta conta. Vou usar aquele método das bolinhas. Pego 100 bolinhas (100\%) e distribuo nelas os 40 morangos. Para cada bolinha vai dar 0,4 morangos. Bem, 0,4 não é nem a metade de um morango. Mas, se eu for somando bolinha por bolinha até chegar um número inteiro, acho que vai dar certo. Entendeu!!??? Tá vou tentar colocar nos mínimos detalhes. Se eu ajuntar 2 bolinhas vai dar 0,8 morangos, mas ainda não é um número inteiro, se eu pegar 3 bol. fica 1,2, se eu pegar 4 bol. fica 1,6, se eu pegar 5 bolinhas fica 2,0, opa...acho que é isso. Cada 5 bolinhas representa 2 morangos, como oito estão podres eu preciso pegar 20 bolinhas. Como cada bolinha representa $1 \%$ e eu peguei 20 bolinhas, então a porcentagem dos morangos podres é de 20\%. Está certo ou eu viajei!?!?!!!? Abraços, H.H.B.!!!!"”

"13/04- Oi, menina! Fico feliz que estais tentando compreender e estudando bastante. Este é o caminho! Parabéns pela opção. Vou detalhar um pouco mais a questão do morango, parecida com aquela que levaste para a sala, das flores.[...]. Como queres descobrir qual a porcentagem, este 100\% pode ser distribuído entre o total de morangos, ou seja, 100\% : $40=2,5 \%$. O que isto significa? Que ao distribuir as 100 bolinhas (o percentual) entre os morangos, cada morango ficou com 2,5 bolinhas, ou 2,5\%. Como se queria saber qual o percentual correspondente a 8 morangos podres, se cada morango equivale a 2,5\%, temos $8 \times 2,5 \%=20 \%$. Ou seja, 20\% dos morangos estavam podres. Essa é outra possibilidade. Traga mais um exemplo e vá explicando. Assim, vais tirando as dúvidas. Beijos, Suely”

Mais ao final da disciplina, a aluna comenta da importância da pergunta em seu processo de aprendizagem:

"12/05- Penso que seja a última vez que eu escreverei aqui, gostei muito de participar do webfólio, foi um pouco diferente do que da lafase, na minha opinião desse semestre foi melhor, pois você questinou mais, estava em cima toda hora...um exemplo é da 
porcentagem, se você não fizesse tanta pergunta, quem sabe eu não teria aprendido tanto porcentagem como aprendi este semestre. Obrigada!!!! Beijos, H.H.B..!!"”

O movimento de aprendizagem desencadeado pela pergunta do professor desestabiliza o aluno da ação de um simples fazer, lançando-o à ação de reflexão, de compreender a ação, de apreender. E "a matéria-prima do professor é o conhecimento. Não é conseguir que o aluno faça isto ou aquilo, mas conseguir que ele compreenda, por reflexionamento próprio, como fez isto ou aquilo" (BECKER, 2001, p.56).

Ao mesmo tempo em que este movimento de aprendizagem e da pergunta esteve presente no espaço de registro e aprendizagem individual das alunas - webfólios individuais -, também esteve presente nos fóruns, no qual as alunas questionaram e se movimentaram na busca de um entendimento mútuo. Nesse espaço, como professora habitante, eu também articulei, orientei e questionei, procurando apreender o movimento do grupo e de cada aluna individualmente. Diferente do movimento de cooperação no webfólio individual, que foi impulsionado em uma direção e dois sentidos (professor $<<>$ aluno), no fórum, este movimento foi desencadeado em várias direções e sentidos, pela professora e pelas alunas.

A aprendizagem em espaços coletivos, como os fóruns de discussão, pode ser gerada por movimentos de cooperação e/ou colaboração. Ao cooperar, segundo Piaget (1973), a troca de proposições constitui uma lógica, pois acarreta em um agrupamento geral devido às correspondências, às reciprocidades ou às complementaridades dos agrupamentos solidários. Um dos papéis do professor em espaços coletivos de discussão, como os fóruns de discussão, é estar atento a tudo e a todos, articulando, orientando e questionando as certezas estabelecidas no grupo de alunos.

Para discutir um pouco mais esse processo, destaco a seguir um debate iniciado no oitavo encontro da disciplina, no ambiente virtual, quando discutíamos o arredondamento de dados numéricos. A cooperação se desencadeou a partir de uma pergunta elaborada por uma das alunas...

"Meninas como fica o arredondamento do valor 6,252? (apenas uma casa decimal). estou esperando as respostas. V.A.” 


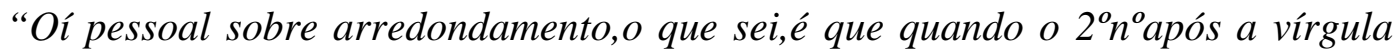
forem maior que 6 o $n^{\circ}$ depois da vírgula aumenta se for menos continua o mesmo.acho que é isso, se estou errada me corrijam. bom vou tentar responder a questão da V.A. COMO o valor que ela nos dá é 6,252,como já falei antes se o valor for maior que 6 aumenta,se for menor continua o mesmo valorque já existia após a vírgula.Então a resposta é 6,2. E. D."

"Veja meu racicinio se esta correto quando eu tenho um número por ex:2,13 e eu desejo arredondar este valor eu posso deixar pelo valor 2.Me lembro que os professores faziam este trabalho, e explicavam o seguinte se $n^{\circ}$ for 2,75 eu posso arredondar para 3,pois é um valor mais aproximado de 3 se for 2,13 eu pooderei arredondar para 2. Tem alguma lógica esta idéia?Se estiver então eu poderei responder que o resultado da pergunta da V.A. é de 6.Pesso ajuda pois eu não sei se expliquei ou se compliquei ainda mais. A.P.”

“... o número que a V.A. nos coloca, se encaixa na regra específica do 5, que diz: quando o primeiro $n^{o}$ a ser abandonado for 5 e o que vier atrás for diferente de zero aumentasse também um $n^{\circ}$ naquele que vem após a vírgula, sendo assim 6,252 fica 6,3. Entretanto no livro (p.49) nos exemplos que tem sobre esta mesma regra de 5 não entendi por que 76,250002 fica 76,3, pois segundo o que entendi depois do 5 não poderia vir o $n^{\circ} 0$ para aumentar 1, gostaria de entender o por quê disso, será que alguém poderia me ajudar? Abraços... M.I."

Apareceram, inicialmente, três proposições diferentes, e percebi que as alunas buscavam o entendimento comum em sua ação comunicativa, gerada pelo movimento de cooperação. E foram surgindo outras proposições... Quando a certeza começou a se estabelecer no grupo, percebi que era o momento de entrar na discussão. Como educadora, procurei resgatar as diferentes proposições, articulando o debate, me posicionando e orientando quanto ao que estavam discutindo...

“Oi, meninas...[...]

Muitas questões foram lançadas e discutidas e posso concluir que muitas conseguem fazer a ligação com a leitura feita. A M.I. e a S.B. justificaram bem a questão do arredondamento do 6,252 para 6,3. Se tiverem dúvidas voltem a mensagem delas. Quanto ao 76,250002 fica 76,3, pois o valor 5 será abandonado (ao se arredondar para uma casa decimal), e tendo qualquer número diferente de zero (no caso é 0002), após o, arredonda-se para mais, ou seja, para 76,3. [..] Observem que não se arredonda pelo abandono da unidade após a vírgula, só se formos arredondar para um número inteiro. $O$ valor a ser abandonado que interessa. Por exemplo, se quero arredondar o valor 3,65879 (para uma casa decimal fica: 3,7; para duas casas decimais fica 3,66; para três casas decimais fica 3,659....). Quem se habilita a justificar cada caso? Suely”

O que se percebe é que aparece a cooperação neste fórum, na busca pela compreensão do ponto de vista do outro, e na abertura para o movimento de eco-organização, possibilitando a auto-organização. Aprender é auto-eco-organizar-se nas relações consigo mesmo, com o outro e com o meio. 
É a partir desses processos, dessa capacidade auto-organizadora da vida, que o indivíduo constrói conhecimento que, por sua vez, não parte nem do mundo do sujeito e nem do mundo do objeto, mas é produto das interações que ocorrem entre ambos. (MORAES, 2003, p.45).

Usarei um dos movimentos de aprendizagem da aluna A.P., ao participar de um fórum, mostrando como ela se auto-organiza ao participar da eco-organização, ou seja, apresentarei o seu movimento de auto-eco-organização. $\mathrm{O}$ movimento de aprendizagem iniciou quando a aluna A.P. se desequilibrou cognitivamente em relação ao conceito de porcentagem, após o seu contato com proposições de colegas e minhas no fórum ...

“20/03 - [...] Eu tenho muitas dúvidas porque eu não entedia porcentagem utilizando regra de trê, e agora piorou,sepossível alguma contribuição sobre porcentagem, pois sei desua importância, porém não compreendo como utiliza-la em sala de aula.[...].Alguém me de uma luz, para clariar minhas dúvidas que são muitas... A.P.”

O momento do desequilíbrio cognitivo estava evidente. Assim, a busca pelo equilíbrio seria iniciada. Segundo Piaget (1995), o restabelecimento do equilíbrio só acontece quando o sujeito acomoda o que é novo, e o que originou o desequilíbrio, às estruturas mentais já existentes. O novo é uma resposta provisória à pergunta que gerou o desequilíbrio cognitivo, e depende das estruturas de assimilação do sujeito. E o desequilíbrio na busca de equilíbrio foi um movimento contínuo...

"22/03 - Professora Suely agora compreendo proque nos questionava sobre regra de tres, o problema nao é usá-la, mas por que usa-la. Penso que a regra de tres é uma forma mais simples e que pode avançar para novos estagios.Nosso grupo discutio a porcentagem de maneira diferente, o que me deixou interessada em descobrir outras coisas sobre estatística e como aplica-la em uma turma de crianças.Agora tentando responder a questao da professora,vamos analisar por partes. Eu A. P. comprei uma calça de $R \$ 38,50$ e ganhei $8 \%$ de desconto qual foi valor da calça. Bem se 38,50 representa $100 \%$ do meu valor e eu quero descobrir 8\% deste como irei chegar ao valor final. Eu dividiria 100 por 8 que daria 12,5 dividindo 38,50 por 12,5 o valor de desconto seria de R\$3,08. A.P.”

A aluna continuou buscando o equilíbrio em interações com outras colegas, comigo, e aos poucos apreendeu a novidade, acomodando o desconhecido ao que era conhecido. Ela cooperou, operando mentalmente com e sobre as suas certezas, e com e sobre as certezas de outros e do meio, buscando o equilíbrio. Depois de várias interações presenciais e no ambiente virtual, a aluna comenta... 
“03/04 - Sbre porcentagem penso que esotu bem, mas existe um ditado que diz o seguinte "Quando achamos que sabemos todas as respostas vêem o tempo e muda nossas perguntas" é assim que estou me sentindo Bem o que eu posso esntender em 10\%, se 1\% representa 1 em cada 100,10\% aseria 10 em cada 100.10 em cada 100 é mesmo que 1 em cada 10. Não é díficil de compreender A conta sobre 10\% em 300. Primeiro descobrir 1\%, 300:100=3. Depois 10x3=30, dando a idéia de um décimo uma fração,sendo mesmo que meio um terço,um quarto...Que se refere a contribuição da E.D. sobre fração... A.P."

O que fiz como professora para que a aluna chegasse a estas conclusões? O meu papel foi de oferecer condições para que ela encontrasse o equilíbrio cognitivo, mesmo que provisório, não dando resposta, mas alimentando a sua dúvida, criando situações que contribuíssem com a sua aprendizagem a partir dos conhecimentos que já possuía. No presencial, criando situações para que ela fosse criando as estruturas necessárias, enquanto também orientava outras 37 alunas da turma, ao mesmo tempo. No espaço virtual pude apreendê-la em seus movimentos nos fóruns e em seu webfólio.

E assim foi se desenvolvendo a disciplina em um processo de educação bimodal. A cada momento presencial, articulado com os movimentos no ambiente virtual, as alunas foram desafiadas a refletir sobre os seus processos de aprendizagem, com o uso de diferentes linguagens. Esses desafios consistiram em movimentos de uso da linguagem oral, a linguagem escrita e/ou iconográfica. Para exemplificar cito o estudo sobre o conceito de porcentagem: Ele iniciou no ambiente virtual, e no encontro presencial seguinte, as alunas foram desafiadas a preparar uma representação escrita e iconográfica de situações que envolvessem o conceito de porcentagem. As ações no ambiente virtual tinham me dado pistas de como as alunas, que habitavam ou visitavam o ambiente, estavam construindo o conceito.

Assim, atenta a todo o processo, ad-mirando para compreender, se constituiu o processo de Educação Bimodal da disciplina. As articulações foram feitas, usando as ações e informações de um ambiente para o planejamento e desenvolvimento de ações no outro ambiente. A articulação entre os espaços resultou em um movimento harmonioso, composto por diferenças, contradições, ações complementares e correspondentes, em que as partes contribuíram para a formação de um todo educacional, uma proposta movimentada pela pergunta, pela dúvida, pela busca, pela certeza, pela compreensão e pela intervenção. 


\section{CONSIDERAÇÕES FINAIS}

O que pude perceber a partir do estudo apresentado ao longo deste artigo é que a estética de Educação Bimodal proposta favoreceu a aprendizagem e o ensino de conteúdos da disciplina de Estatística Aplicada à Educação, sendo esta compreendida não como um fim em si mesma, mas como uma atividade que contempla diferentes movimentos e saberes. Os elementos essenciais desta estética são: as atitudes do educador ou educadora, identificadas como relevantes para aprendizagens e reflexões em uma proposta de Educação Bimodal; a atitude dos alunos e alunas frente ao processo de aprendizagens e comunicações no processo de Educação Bimodal; e a contribuição da estética do material impresso e do ambiente virtual para a aprendizagem dos alunos em relação aos conteúdos discutidos. Esses elementos podem perpassar a estética de qualquer disciplina a ser ofertada em um sistema bimodal de educação.

O objetivo deste artigo foi o de apresentar e analisar uma estética para a Educação Bimodal, identificando atitudes, espaços e ações de educadores e educandos que favoreçam aprendizagens e comunicações em ambientes presencias e virtuais, coerente com a estética da complexidade. Mas que atitudes são estas? Que ações são estas? Que espaços são estes? Algumas atitudes, ações e espaços foram sinalizados ao fazer a análise com o grupo de alunas, sujeitos da pesquisa, outros necessitam de novas pesquisas. Nestas buscas, é preciso apenas reconhecer-se como habitante, visitante ou transeunte, para então poder escolher o seu caminho e os seus parceiros. O desafio do educador e educadora está em conseguir habitar e articular, ao mesmo tempo, vários espaços e saberes, "ad-mirando" e apreendendo cada movimento do educando, para gerar neste o movimento da auto-eco-organização, aprendendo consigo mesmo, com o outro, com o meio e com as diferentes histórias, transformando e transformando-se continuamente, não de forma linear, mas hipertextual e complexa.

O estudo que desenvolvi neste artigo, recorte de minha tese de doutorado, é apenas uma contribuição para os vários trabalhos que estão sendo desenvolvidos na área de Educação a Distância, Educação Bimodal e aprendizagem em ambientes virtuais, a partir das possibilidades e disponibilidades de tecnologias que temos acessos nos mais diferentes espaços da sociedade, escolas e universidades. Aqui, usei apenas algumas tecnologias de comunicação e informação, com um modelo específico de ambiente virtual. Temos de pensar, entretanto, na estética da Educação Bimodal com o uso de outras tecnologias e possibilidades, pois limitar não é o que se busca ao viver o paradigma da complexidade. A unidade complexa 
não anula a variedade e a diversidade das complexidades que a tecem, ela é formada pela junção de elementos que lutam entre si, e que se entrelaçam para formá-la.

O que busquei com a pesquisa apresentada aqui foi contribuir para o estudo de uma estética de educação mais híbrida, mais mista, mais coerente, com mais rigor, mais complexa, mais harmoniosa, sem deixar de possuir elementos antagônicos, mais sistêmica, mais livre, mais crítica. Ambientes educacionais onde todos se sintam e sejam livres e contribuam livremente, de forma comprometida e responsável, na formação de cada um e de um todo em movimento, que aos poucos ganha e emana uma grande força, de ser, de conhecimento, de transformação. Uma educação matemática, um processo de formação de professores, com o uso de tecnologias da informação e da comunicação, que busque a liberdade, a reflexão, o coletivo, sem perder de vista o individual, a pergunta, a mudança.

\section{REFERÊNCIAS}

BECKER, F. Educação e construção do conhecimento. Porto Alegre: Artmed Editora, 2001. 125p. 2003. $115 p$

A origem do conhecimento e a aprendizagem escolar. Porto Alegre: Artmed,

FAZENDA, I. C. A. (Org.). Dicionário em construção: interdisciplinaridade. São Paulo, SP: Cortez, 2001. 272p.

Interdisciplinaridade: qual o sentido? São Paulo, SP: Paulus, 2003. 84p.

FREIRE, P. Extensão ou comunicação? 10.ed. Traduzido por Rosisca Darcy de Oliveira. Rio de Janeiro, RJ: Paz e Terra, 1992. 93p.

À sombra desta mangueira. São Paulo, SP: Olho d'Água, 2001.120p.

MAFFEZOLI, M. No fundo das aparências. 2.ed. Tradução de Bertha Halpern Gurovitz. Petrópolis: Vozes, 1999. 350p.

MATURANA R., H. Emoções e linguagem na educação e na política. Tradução por José Fernando Campos Fortes. 2.ed. Belo Horizonte: Editora UFMG, 2001. 98p.

MORIN, E. et al. Educar na era planetária: o pensamento complexo como método de aprendizagem no erro e na incerteza humana. Tradução de Sandra Trabucco Valenzuela. São Paulo, SP: Cortez: Brasília: UNESCO, 2003. 111p. 
PIAGET, J. Estudos sociológicos. Tradução de Reginaldo Di Piero. Rio de Janeiro, RJ: Forense, 1973. 231p.

. Abstração reflexionante: relações lógico-aritméticas e ordem das relações espaciais. Tradução por Fernando Becker e Petronilha Beatriz Gonçalves da Silva. Porto Alegre: Artes Médicas, 1995. 292p.

RAMAL, A. C. Educação na cibercultura: Hipertextualidade, Leitura, escrita e Aprendizagem. Porto Alegre: Artmed, 2002. 268p.

SCHERER, S. Estatística aplicada à educação. Jaraguá do Sul - SC: UNERJ, 2004. 73p

Uma estética possível para a educação bimodal: Aprendizagem e Comunicação em Ambientes Presenciais e Virtuais (Uma experiência em Estatística Aplicada à Educação). 2005. 240f. Tese (Doutorado em Educação: Currículo) - Pontifícia Universidade Católica de São Paulo, São Paulo.

SOLETIC, A. A produção de Materiais Escritos nos Programas de Educação a Distância: Problemas e Desafios. In: LITWIN, E. (Org.). Educação a distância: temas para o debate de uma nova agenda educativa. Tradução por Fátima Murad. Porto Alegre: Artmed, 2001. p. 7392.

VALENTE, J. A. Educação a Distância: uma oportunidade para mudança no ensino. In: MAIA,C. (Org.). ead.br: Educação a distância no Brasil na era da Internet. São Paulo, SP: Anhembi Morumbi Editora, 2000. p. 97-12 
SUELY SCHERER

Professora e coordenadora de Educação a Distância e do curso de

Pedagogia no Centro Universitário de Jaraguá do Sul. Professora colaboradora na UFPR, no Programa de Pós-Graduação em Educação. (47)

9973-5028

E-mail: susche@gmail.com

Recebido em: 13/01/2009

Publicado em: 30/06/2009 